Prepared for the U.S. Department of Energy

under Contract DE-AC05-76RL01830

\title{
Skyshine Contribution to Gamma Ray Background Between 0 and 4 MeV
}
AL Mitchell
RT Kouzes
JD Borgardt

August 2009

\section{Pacific Northwest}

NATIONAL LABORATORY

Proudly Operated by Battelle Since 1965 


\title{
DISCLAIMER
}

This report was prepared as an account of work sponsored by an agency of the United States Government. Neither the United States Government nor any agency thereof, nor Battelle Memorial Institute, nor any of their employees, makes any warranty, express or implied, or assumes any legal liability or responsibility for the accuracy, completeness, or usefulness of any information, apparatus, product, or process disclosed, or represents that its use would not infringe privately owned rights. Reference herein to any specific commercial product, process, or service by trade name, trademark, manufacturer, or otherwise does not necessarily constitute or imply its endorsement, recommendation, or favoring by the United States Government or any agency thereof, or Battelle Memorial Institute. The views and opinions of authors expressed herein do not necessarily state or reflect those of the United States Government or any agency thereof.

\author{
PACIFIC NORTHWEST NATIONAL LABORATORY \\ operated by \\ BATTELLE \\ for the \\ UNITED STATES DEPARTMENT OF ENERGY \\ under Contract DE-AC05-76RL01830
}

Printed in the United States of America
Available to DOE and DOE contractors from the Office of Scientific and Technical Information,
P.O. Box 62, Oak Ridge, TN 37831-0062;
ph: (865) 576-8401
fax: $(865) 576-5728$
email: reports@adonis.osti.gov

\footnotetext{
Available to the public from the National Technical Information Service, U.S. Department of Commerce, 5285 Port Royal Rd., Springfield, VA 22161 ph: (800) 553-6847 fax: $(703) 605-6900$ email: orders@ntis.fedworld.gov online ordering: http://www.ntis.gov/ordering.htm
}

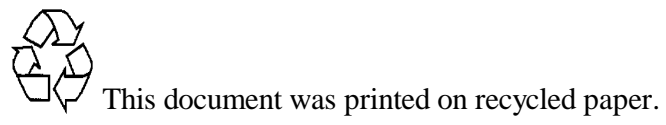




\title{
Skyshine Contribution to Gamma Ray Background Between 0 and 4 $\mathrm{MeV}$
}

\author{
AL Mitchell $\quad$ RT Kouzes \\ JD Borgardt
}

August 2009

Prepared for

the U.S. Department of Energy

under Contract DE-AC05-76RL01830

Pacific Northwest National Laboratory

Richland, Washington 99352 


\begin{abstract}
Natural gamma-ray background is composed of four components; which include cosmic rays, cosmic ray produced atmospheric activity, terrestrial sources, and skyshine from terrestrial sources. Skyshine is radiation scattered from the air above a source that can produce a signal in radiation detection instrumentation. Skyshine has been studied for many years but its contribution to the natural background observed in a detector has not been studied. A large $\mathrm{NaI}(\mathrm{Tl})$ detector was used to investigate each of the four components of the natural background using a series of 48-hour measurements and appropriate lead shielding configured to discriminate contributions from each component. It was found that while the contribution from skyshine decreases rapidly with energy, it represents a significant portion of the background spectrum below $\sim 500 \mathrm{keV}$. A similar campaign of measurements using a HPGe detector is underway.
\end{abstract}




\section{Introduction}

Natural gamma-ray background radiation originates from four distinct components: cosmic ray shower events, cosmic ray produced atmospheric activity, terrestrial sources, and skyshine from terrestrial sources. The first of these, cosmic rays, are energetic particles of extraterrestrial origin that enter the Earth's atmosphere [1]. The primary cosmic radiation is made up of charged particles, predominantly protons, and heavy ions that have energy spectra extending into the GeV range and beyond [2]. Cosmic sources can vary with the solar cycle and are influenced by latitude, barometric pressure, solar activity, diurnal cycle, and weather [3]. This primary cosmic radiation interacts with the atmosphere, generating a shower of very high energy secondary particles that includes mesons, electrons, protons, neutrons and photons. At the Earth's surface this secondary cosmic radiation is narrowly collimated along the line of the original radiation. Fast neutrons from cosmic interactions can also create additional gamma rays [4]. The second component, atmospheric activity, results from a continuous production of cosmic ray generated unstable isotopes, including a roughly constant level of ${ }^{14} \mathrm{C}$ which permits radiocarbon dating, as well as gaseous ${ }^{222} \mathrm{Rn}$ emitted terrestrially as part of the ${ }^{238} \mathrm{U}$ decay chain. The third contributor, terrestrial background radiation, is low intensity gamma radiation from the ground that results from the naturally occurring radioactive decay of isotopes of uranium and thorium and their daughters, and potassium $\left({ }^{40} \mathrm{~K}\right)$. Terrestrial background sources can vary spatially due to the materials in the soil and temporally due to changes in the weather primarily affecting the release of gaseous ${ }^{222} \mathrm{Rn}$ from the soil [5].

The final contributor to the background, and the least studied, is known as skyshine. This represents atmospheric scattering of radiation from terrestrial background components (or, in general, from man-made sources as well). Skyshine from terrestrial sources has been considered 
a negligible contributor in most detection applications. However, skyshine from man-made sources on the ground, including accelerators [6], medical sources [7] and industrial sources [8] has disrupted specialized detection efforts in the surrounding area. This has been a recent concern in areas such as the ongoing effort to detect illicit nuclear sources at US border crossings and seaports. This motivated the effort reported in this paper to attempt to quantify the contribution of skyshine, in the absence of man-made sources, to the natural background. Very little research has been carried out on this subject, particularly in the $0-4 \mathrm{MeV}$ range. Published results have dealt with quantifying the terrestrial and cosmic components, and considered skyshine to have little impact even in the lower energy regions (see, for example, Figure 1). The purpose of this work was to measure the various components of natural background in the 0-4 $\mathrm{MeV}$ range using a $\mathrm{NaI}(\mathrm{Tl})$ detector, to segregate the individual components, and to provide some quantification as to the impact of each component to background radiation, and particularly to characterize the relevance of skyshine over this energy span. 


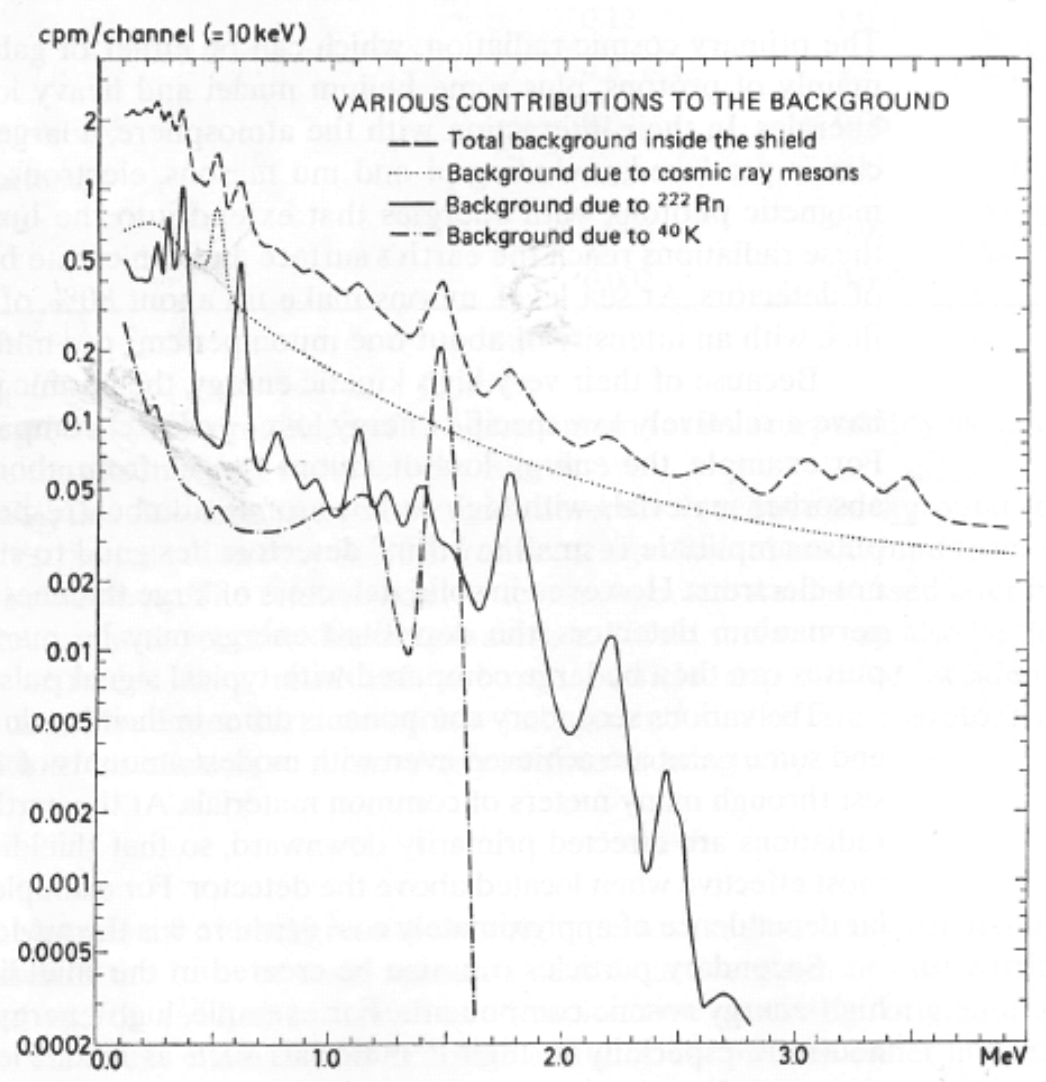

Figure 1. Sample graph of various components of background radiation [4]

\section{Materials and Methods}

Preliminary measurements were made at 18 outdoor sites within a $350 \mathrm{~m}$ radius around the external site selected for measurements to assess the degree of uniformity of background radiation in the vicinity. An unshielded electrically cooled high purity germanium (HPGe) detector (Ortec Detective) collected the background over a 7-minute run at each location.

With one exception, the subsequent measurements to quantify background contributors were made at a single site, selected by virtue of its $300 \mathrm{~m}$ distance from any structures, and greater than $350 \mathrm{~m}$ separation from the nearby Columbia River. A 4"x 4"x 16" thallium-doped sodium iodide $(\mathrm{NaI}(\mathrm{Tl})$ ) detector (Scionix Holland, 3.5N-E2-X) was used. The detector was 
computer-interfaced using an Ortec digiBASETM, and data were collected utilizing multi-channel analyzer emulation software (Ortec Maestro-32 v6.08). A portable generator was used to supply power for the setup. Each measurement was made over a continuous 48-hour period, with the exception of data collected on a boat on the Columbia River over an 11-hour period. Various configurations of $\geq 6$ " thick lead shielding were arranged as detailed in the following sections, and summarized in table 1.

\begin{tabular}{|l|l|}
\hline \multicolumn{2}{|l|}{ Table 1. Summary of data runs } \\
\hline \multicolumn{1}{|c|}{ Site (Duration) } & \multicolumn{1}{c|}{ Lead Shielding } \\
\hline Land (48 hrs) & No shielding \\
\hline Land (48 hrs) & $\geq 6$ " on all six sides \\
\hline Land (48 hrs) & $\geq 6$ " on five sides - bottom open \\
\hline Land (48 hrs) & $\geq 6$ " on five sides - top open \\
\hline Boat (11 hrs) & $\geq 2$ " on four lateral sides \\
\hline
\end{tabular}

Table 1. Summary of runs and the lead shielding configuration used for each case

\section{Unshielded Configuration}

The detector was placed on a tarp on the ground at the primary site with no lead shielding in order to collect an unobstructed spectrum of the natural background (Figure 2).

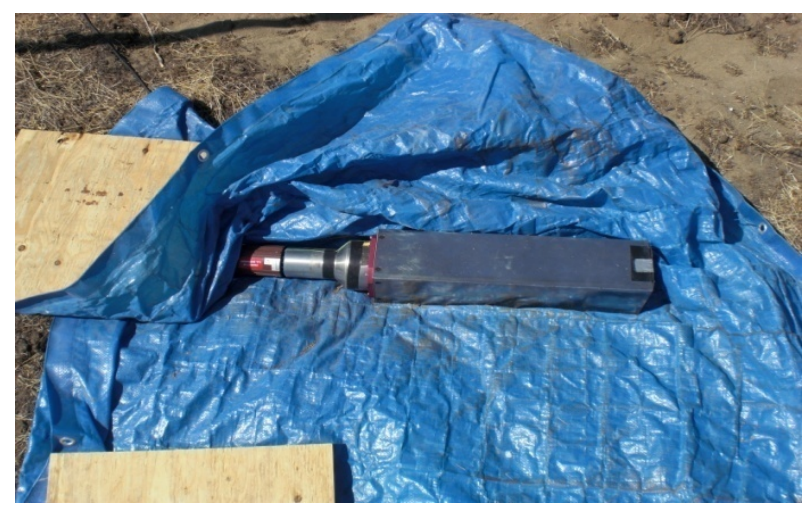


Figure 2. NaI(Tl) detector with no shielding

\section{Shielded on All Sides}

An attempt to shield all components of the natural background was made by completely encasing the detector in $\geq 6$ " of lead bricks (Figure 3). The enclosure of the detector allowed for a measure of the low level radiation emitted by the detector and the lead, along with any leakage through the shielding. The layers of lead were arranged in an alternating pattern to cover various seams in the configuration, and minimize leakage of the natural background.

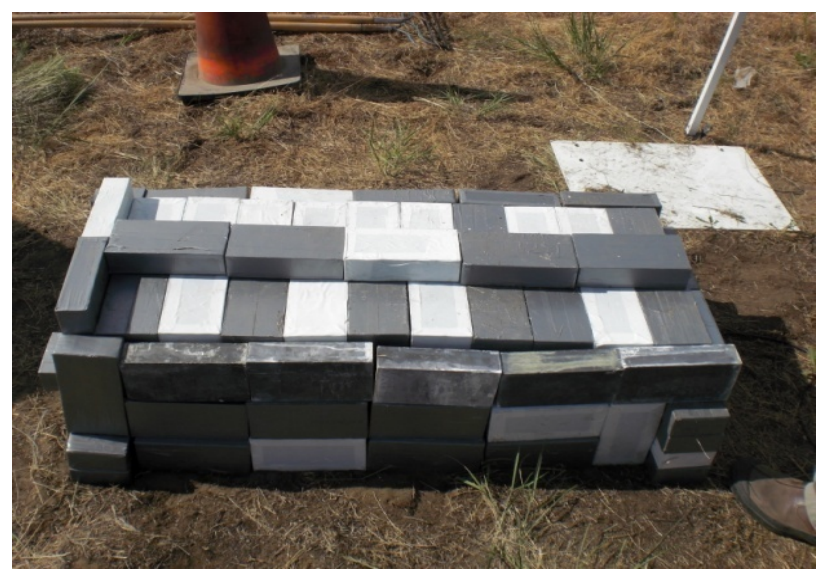

Figure 3. $\mathrm{NaI}(\mathrm{Tl})$ detector completely encased in $\geq 6$ " of lead 


\section{Terrestrial Component Measurement}

The detector was placed directly on the ground and $\geq 6$ " of lead bricks were placed on the remaining 5 sides of the detector to measure the terrestrial component of background radiation. Figure 4 shows this set-up prior to two supportive steel plates and a 6" layer of lead bricks being placed on the top of the lower tier of lead bricks. The arrangement was designed to help shield the detector from the cosmic and skyshine components of the natural background.

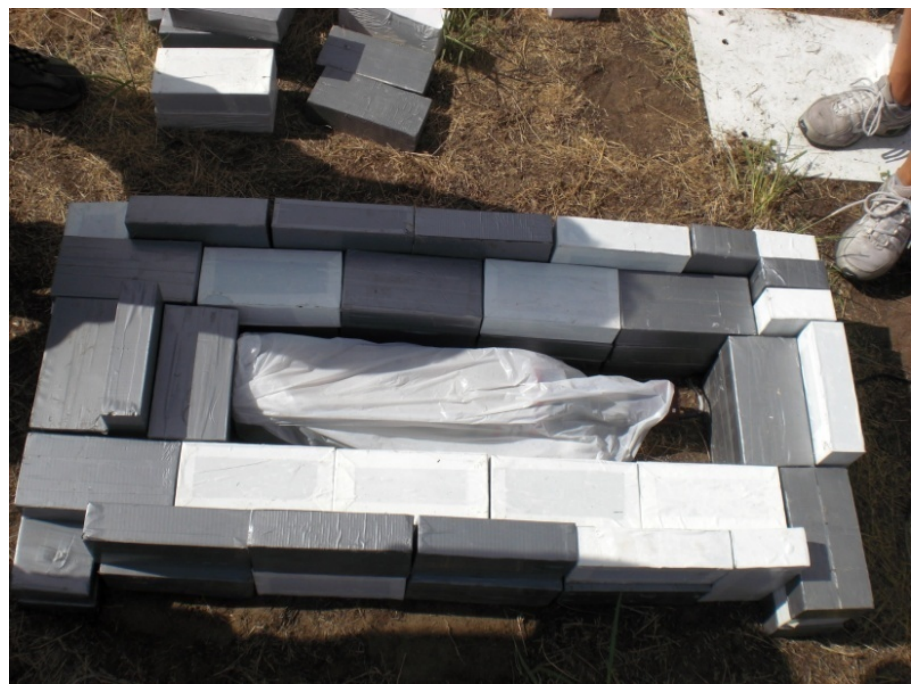

Figure 4. $\mathrm{NaI}(\mathrm{Tl})$ detector prior to the placement of steel plates and lead "roof". For this measurement the detector was shielded on 5 sides, with only the downward ground-facing panel being unshielded 


\section{Cosmic and Skyshine Measurement}

The detector was housed in $\geq 6$ " of lead bricks covering the ground and four lateral sides, leaving only the top exposed, in order to measure the atmospheric (skyshine and cosmic) components of background radiation, minimizing the terrestrial component (Figure 5).

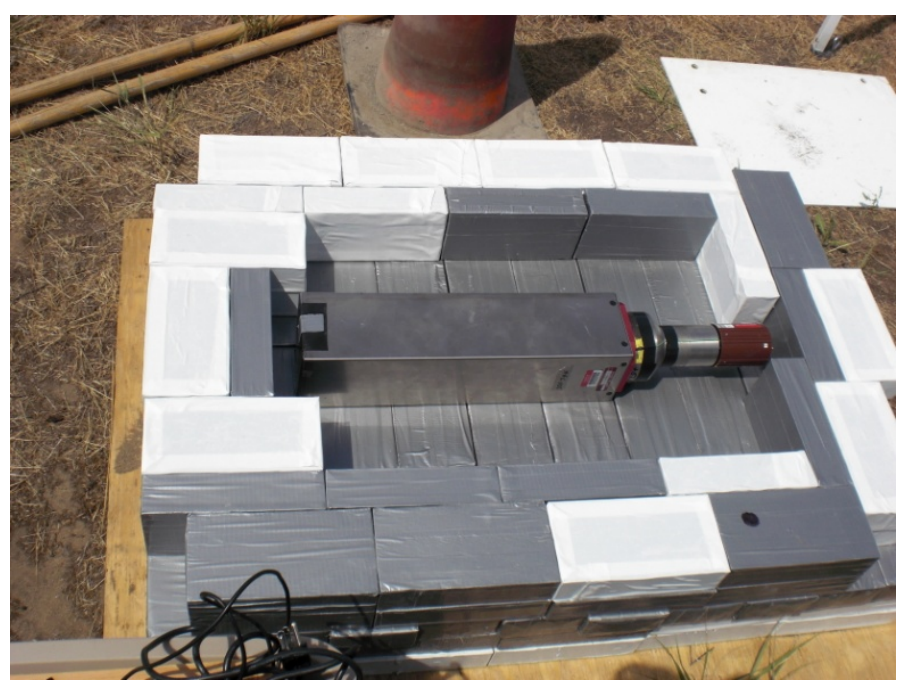

Figure 5. $\mathrm{NaI}(\mathrm{Tl})$ detector shielded on 5 sides, with the top open, to measure the skyshine and cosmic components of background

\section{Cosmic Component Measurement}

To separate the cosmic components, both primary and secondary, from the terrestrial and skyshine contributions, measurements were made on the Columbia River at a sufficient distance from land so that air scatter (skyshine) from ground sources and direct terrestrial radiation were negligible. It is reported that skyshine falls off to $<0.01 \%$ at about $600 \mathrm{~m}$ from a source [8]. The boat was anchored in $\sim 10 \mathrm{~m}$ of water at a position that was $>1000 \mathrm{~m}$ laterally from land and any structures (location shown in Figure 6). Two to four inches of lead was placed around the side perimeter of the detector to provide additional shielding from any potential terrestrial 
contribution (Figure 7). With the skyshine and terrestrial components minimized, this scenario was considered to allow the collection of the cosmic component, however there may be some contribution from radon, as well as some gamma radiation of terrestrial origin.

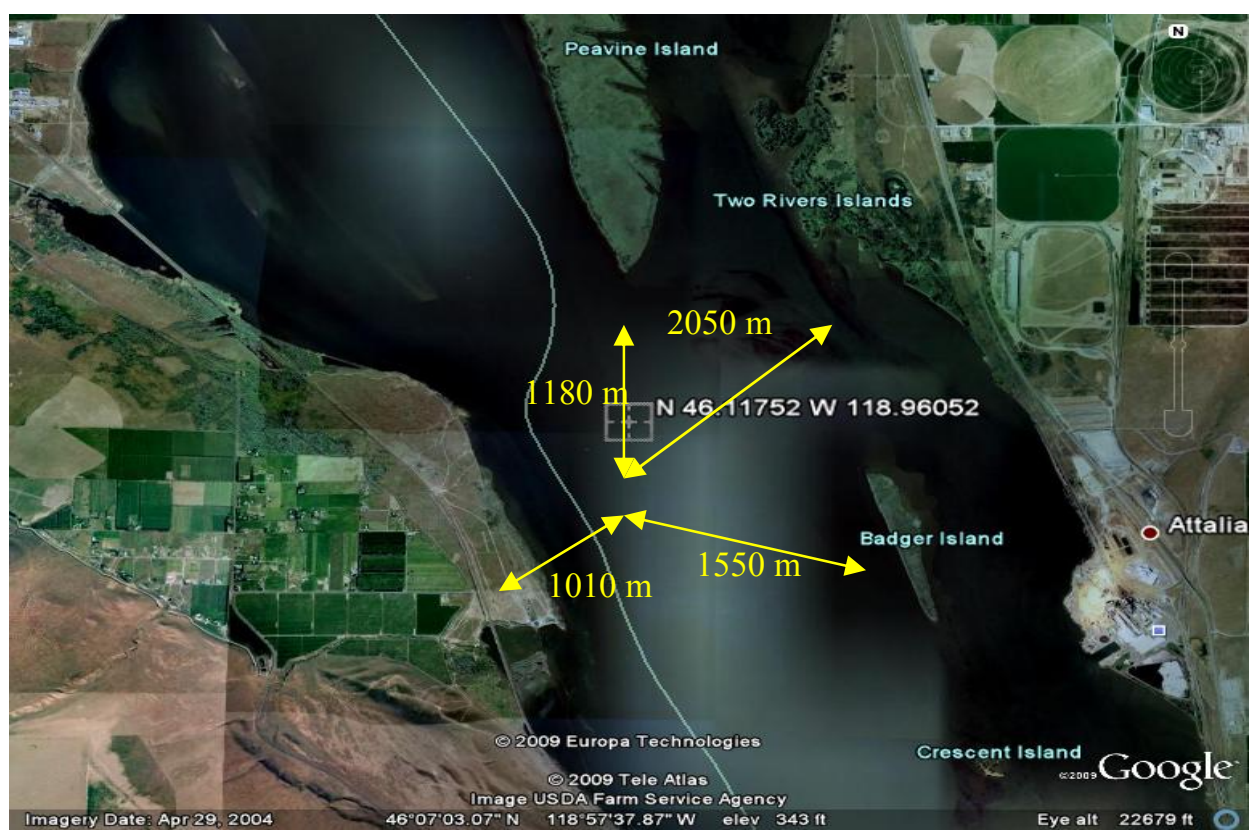

Figure 6. Location of the boat and the $\mathrm{NaI}(\mathrm{Tl})$ detector on the Columbia River 


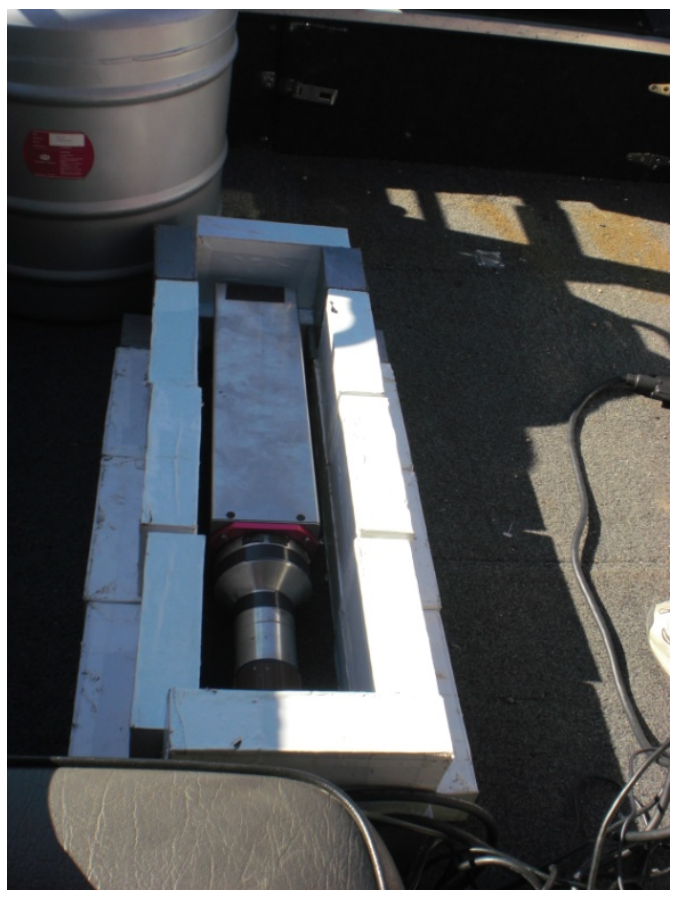

Figure 7. $\mathrm{NaI}(\mathrm{Tl})$ detector situated on the boat for cosmic ray component measurements

\section{Results and Analysis}

The preliminary measurements collected around the primary site used for the natural background measurements showed no significant change of background composition between each location surveyed, with one exception. The spectrum for each location yielded a similar signature along with comparable energy peaks. The results from HPGe measurements for two locations, at the main measurement site and $300 \mathrm{~m}$ east of the site, are shown in figure 8 for comparative purposes. Both prominently exhibit the $1462 \mathrm{keV}^{40} \mathrm{~K}$ and the $2614 \mathrm{keV}^{208} \mathrm{Tl}$ (Th decay chain) peaks. 


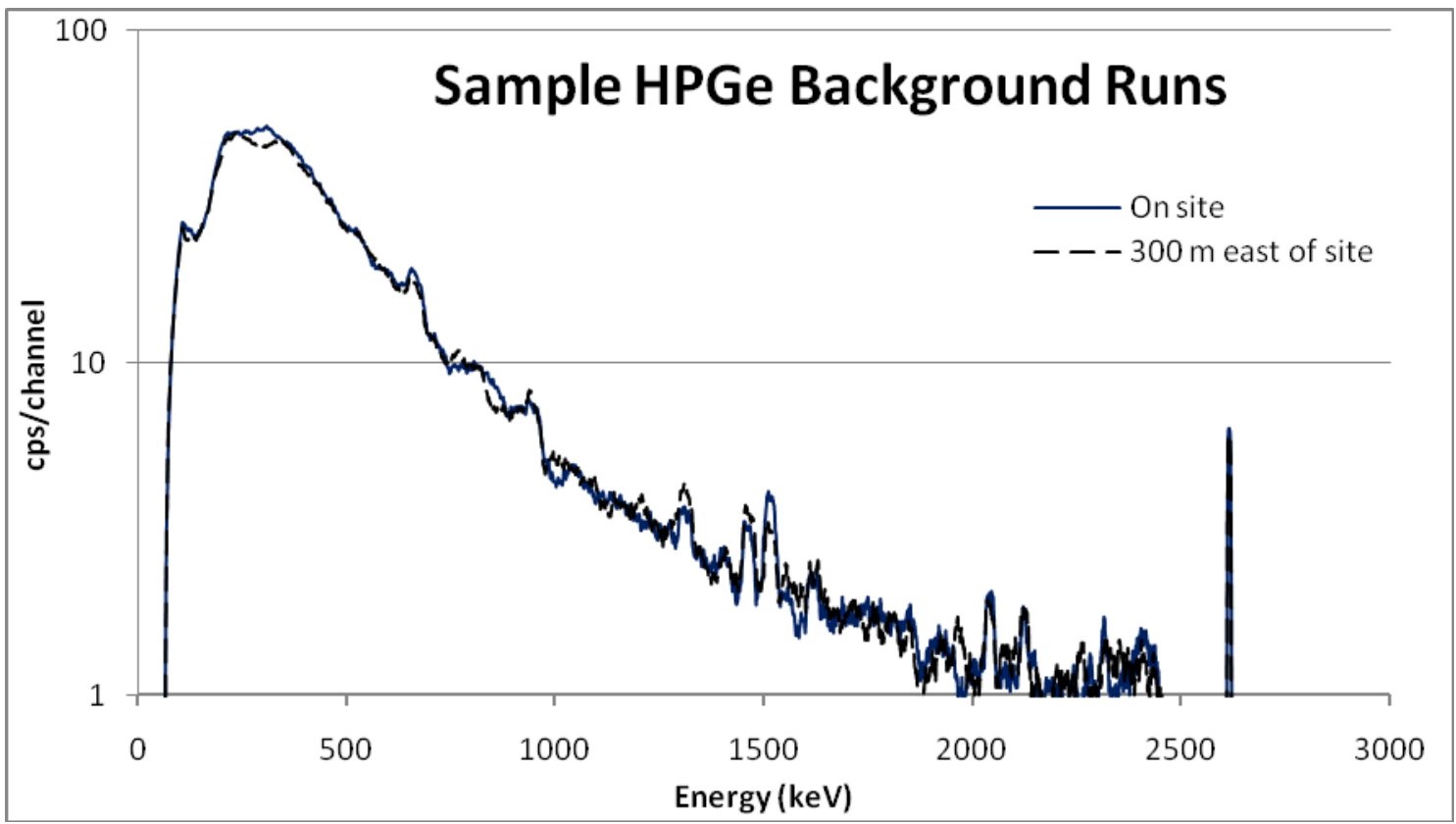

Figure 8. Comparative graph of two sites showing consistency of the HPGe preliminary background measurements in the surrounding area

The total count rate of each measurement was compared to the averaged count rate across all eighteen runs. The observed variations were less than $3.5 \%$ with the exception of one outlier with a $\sim 8.0 \%$ difference. Similar energy signatures were found in each case. The signal of the outlier was suppressed across the energy range tested. This particular data set was collected on the edge of an unpaved, compacted ground access road which had two standard Conex shipping containers situated $\sim 20$ yds away. These represent plausible causes of a lower count rate as, in general, data collected on natural sites exhibited slightly higher count rates, while those made near paved or compacted roads were slightly reduced.

For the natural background measurements a periodic gain shift, sometimes pronounced, was seen throughout the 48 hour period. The shift appeared as a sinusoidal variation, likely temperature dependent in origin. The peaks drifted to higher channels throughout the night when the temperature was low, and then to lower channels during the day when the temperature 
increased. Figure 9 displays the largest variation, approximately 55 channels on a 1024 scale for the $1462 \mathrm{keV}^{40} \mathrm{~K}$ peak, over a 12 hour period. The gain shift was adjusted through a recursive fit based on at least four prominent energy peaks ( $239 \mathrm{keV}, 609 \mathrm{keV}, 1462 \mathrm{keV}$, and $2614 \mathrm{keV})$ for runs featuring a terrestrial component. For data sets not including a ground signature a less exact linear adjustment was made.

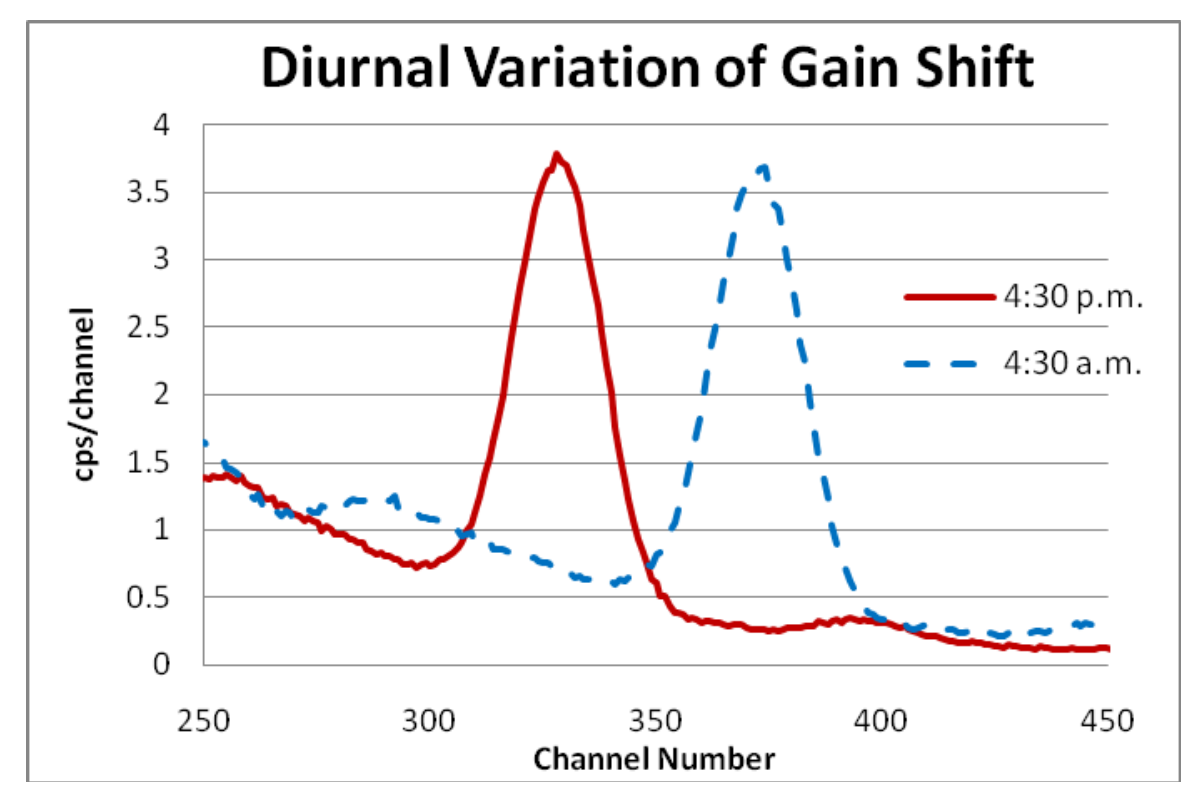

Figure 9. Diurnal shift of the ${ }^{40} \mathrm{~K}$ peak over a 12 hour time frame observed in $\mathrm{NaI}(\mathrm{Tl})$

The unshielded configuration of the detector measured all components of natural background over the $0-4 \mathrm{MeV}$ energy window (Figure 10). The three main terrestrial signatures include the ${ }^{40} \mathrm{~K} 1462 \mathrm{keV}$ line, the ${ }^{214} \mathrm{Bi} 1760 \mathrm{keV}$ line from the uranium decay chain, and the ${ }^{206} \mathrm{~T} 12614 \mathrm{keV}$ line from the thorium decay chain. A cosmic ray and skyshine contribution is also seen in the low energy range down to the lower level descriminator at $\sim 40 \mathrm{keV}$. There are also other noticable peaks including the ${ }^{212} \mathrm{~Pb} 239 \mathrm{keV},{ }^{209} \mathrm{Bi} 609 \mathrm{keV},{ }^{208} \mathrm{Tl} 908 \mathrm{keV}$, and ${ }^{214} \mathrm{Bi}$ $1120 \mathrm{keV}$ lines, which arise from terrestrial sources. 


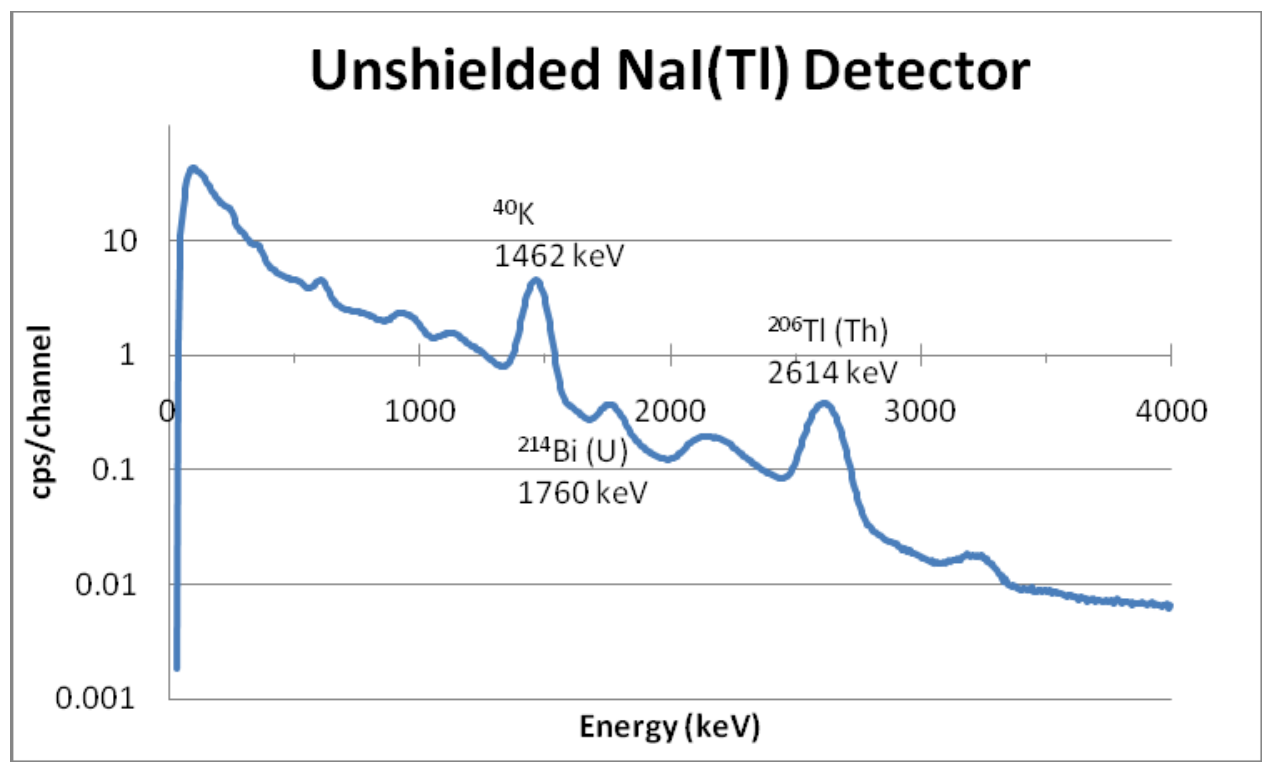

Figure 10. Gain shift corrected $\mathrm{NaI}(\mathrm{Tl})$ spectrum for the total 48-hour period with no shielding

Results for the detector being completely encased in $\geq 6$ " of lead show a reduction in the count rate, particularly in the low energy region (Figure 11). In comparison to the unshielded data shown in figure 10, the prominent energy peaks are suppressed and the count rate at low energies is reduced by over two orders of magnitude. The reduction decreases at higher energies, as expected. The shielded background data in figure 11 allow an estimate of the radiation emitted by the detector and lead, as well as any leakage that may have occurred. 


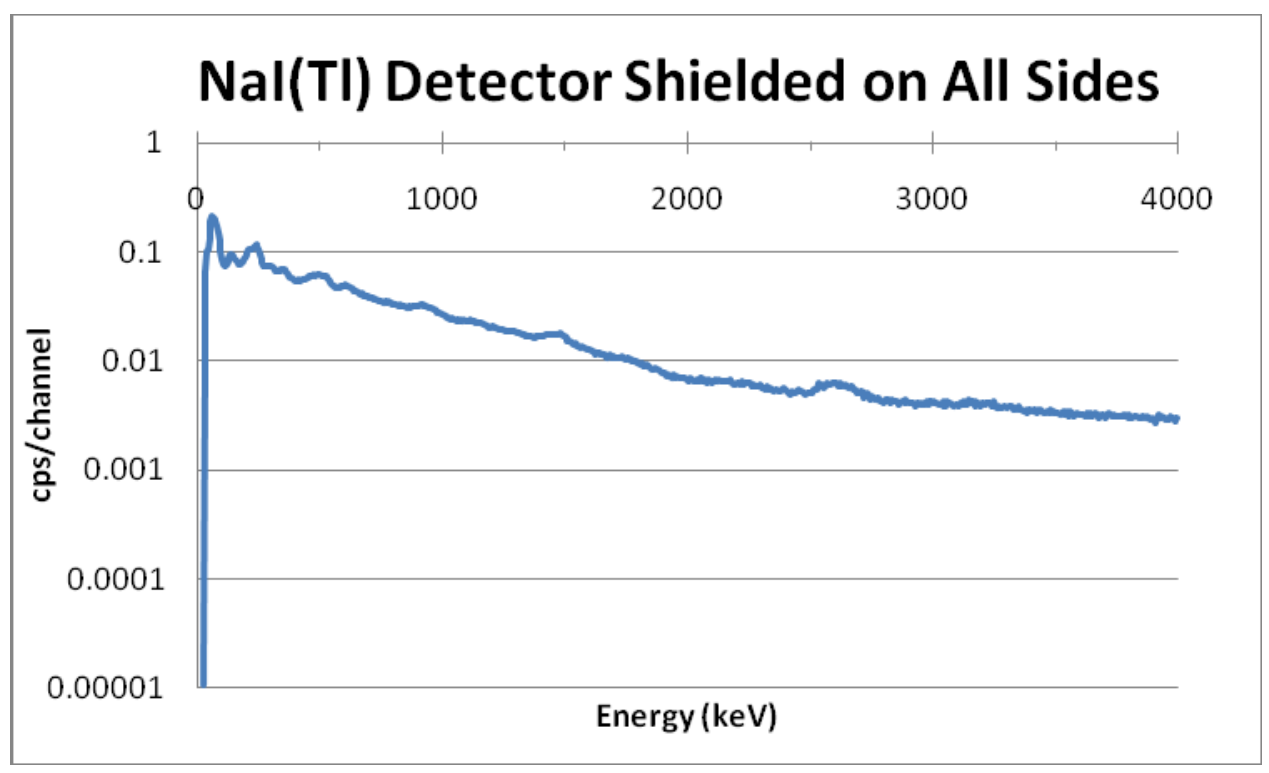

Figure 11. Gain shift corrected $\mathrm{NaI}(\mathrm{Tl})$ spectrum for the total 48-hour period with shielding on all sides

Data for the contribution of the terrestrial signature is shown in figure 12 , which shows net (background, Figure 11, subtracted) results geometrically corrected to account for the signal suppression due to the lateral lead shielding obstructing the desired $2 \pi$ field of view. Corrections were not made for aspects such as large angle downscattering, which were assumed to be a lower order adjustment and to not impact the general findings of this work. Comparison to figure 10 illustrates that terrestrial sources represent a large contributing factor to natural background at all energies. The three main contributors previously noted, ${ }^{40} \mathrm{~K},{ }^{214} \mathrm{Bi}$, and ${ }^{206} \mathrm{Tl}$ are clearly discernable. As expected, each of these peaks was seen in the unshielded measurement and suppressed in the shielded measurement. 


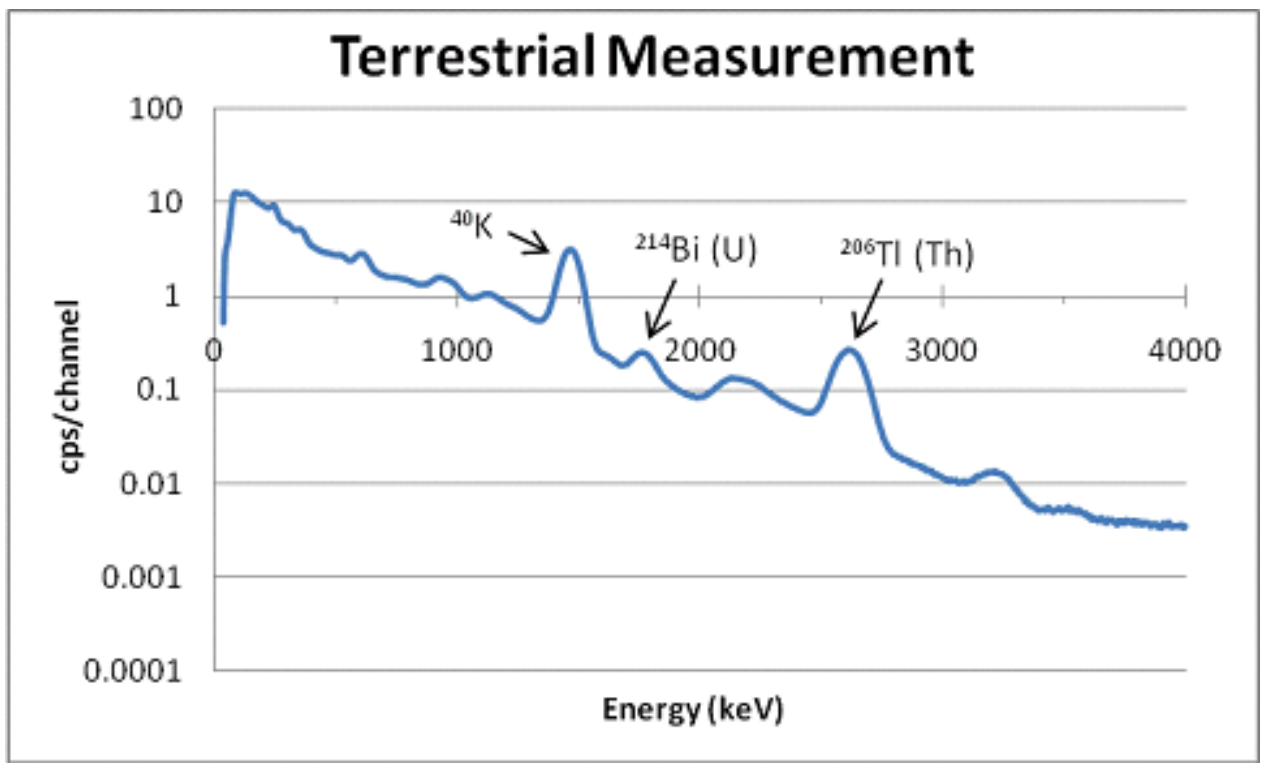

Figure 12. Gain shift corrected $\mathrm{NaI}(\mathrm{Tl})$ spectrum for the total 48-hour period for the terrestrial component

Cosmic and skyshine contributions to natural background (Figure 13) are significant in the low energy ranges of $0-\sim 500 \mathrm{keV}$ but dies off quickly to below $0.1 \mathrm{cps} /$ channel for $>\sim 650$ $\mathrm{keV}$. As in the terrestrial case, the data represent net (shielded background subtracted) results incorporating a geometric adjustment to correct for the reduction in solid angle due to the lateral shielding. From the maximum in the measured spectrum at $\sim 50 \mathrm{keV}$, there is a three order of magnitude reduction in the count rate by $\sim 650 \mathrm{keV}$. The spectra shows broad weak peaks due to a terrestrial, radon or cosmic contribution, but in general the signature is structureless. 


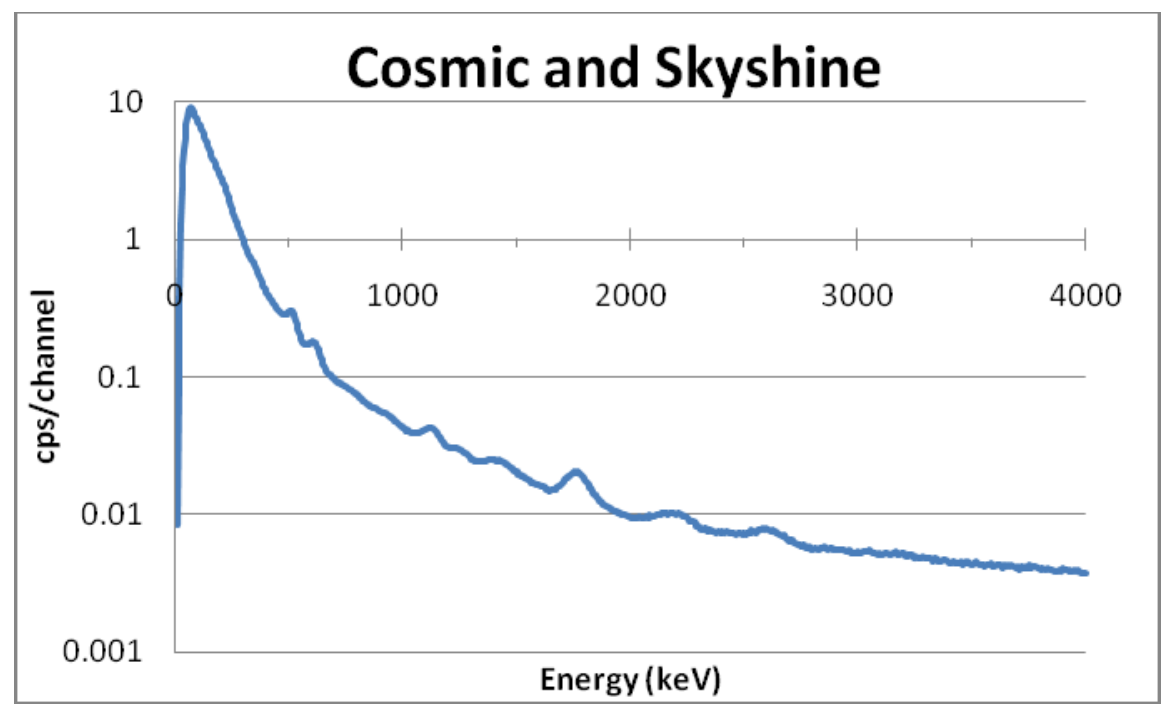

Figure 13. Gain shift corrected $\mathrm{Na}(\mathrm{Tl})$ spectrum for the total 48-hour period for the cosmic and skyshine components

The cosmic ray contribution (Figure 14), taken on the river, to the natural background is at least one order of magnitude less at low energies than other measured source contributions, and is only $\sim 3$ times the count rate for the completely shielded detector (Figure 11) in this energy regime. As in prior cases, the shielded background (Figure 11) is subtracted, however in this case since the "shielding" was largely accomplished by locale, no geometric correction was made.

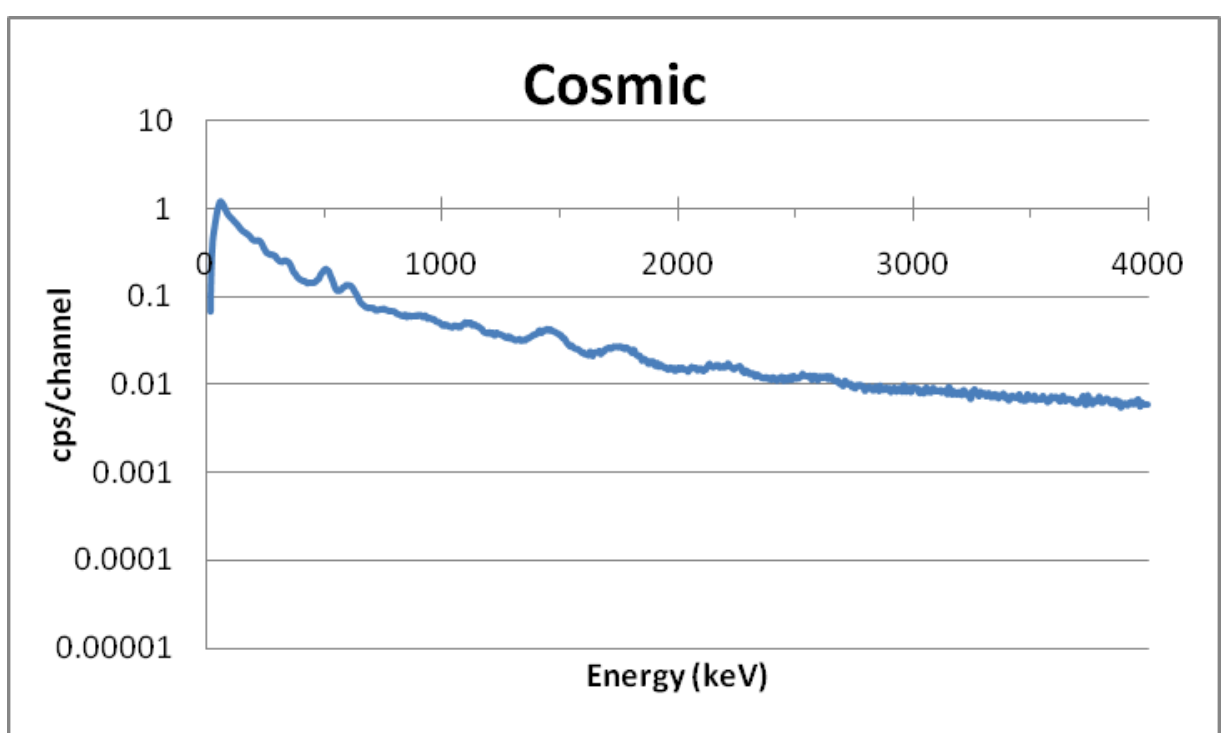

Figure 14. Spectrum for the total 48-hour period of the cosmic rays component 
Cosmic rays (Figure 14) are a small contributing factor in the low energy range with the peak reaching only $\sim 1 \mathrm{cps} /$ channel, whereas the combination of cosmic rays and skyshine (Figure 13) reaches a peak of $\sim 10 \mathrm{cps} / \mathrm{channel}$. These plots are overlaid in figure 15 for comparative purposes, and imply that skyshine is the dominant component in this spectrum for energies $<\sim 700 \mathrm{keV}$.

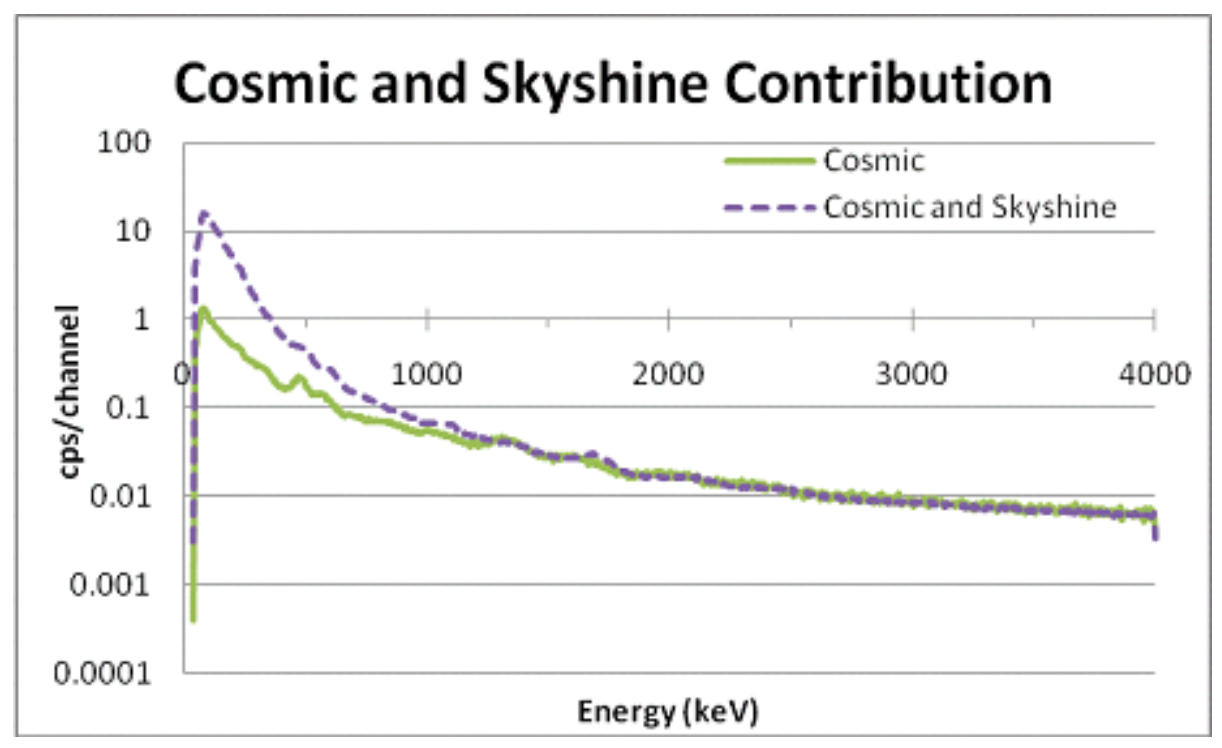

Figure 15. Comparision of cosmic and skyshine contribution

Summary data are compiled in figure 16. Data for the terrestrial component and net unshielded background correlate extremely well above an energy of $\sim 500 \mathrm{keV}$ indicating that, as expected, the terrestrial source represents the principal contributor to the overall background on land at energies between $\sim 500 \mathrm{keV}-3000 \mathrm{keV}$. However, these two data sets are divergent below $\sim 500 \mathrm{keV}$, indicating other important contributors to the total background in this energy regime. As discussed above, compared to the the unshielded background the cosmic component is a minor factor over the $0-3 \mathrm{MeV}$ energy range, and particularly so in a relative sense $<500 \mathrm{keV}$, contributing $\sim 1 \mathrm{cps} /$ channel (Figure 14). 


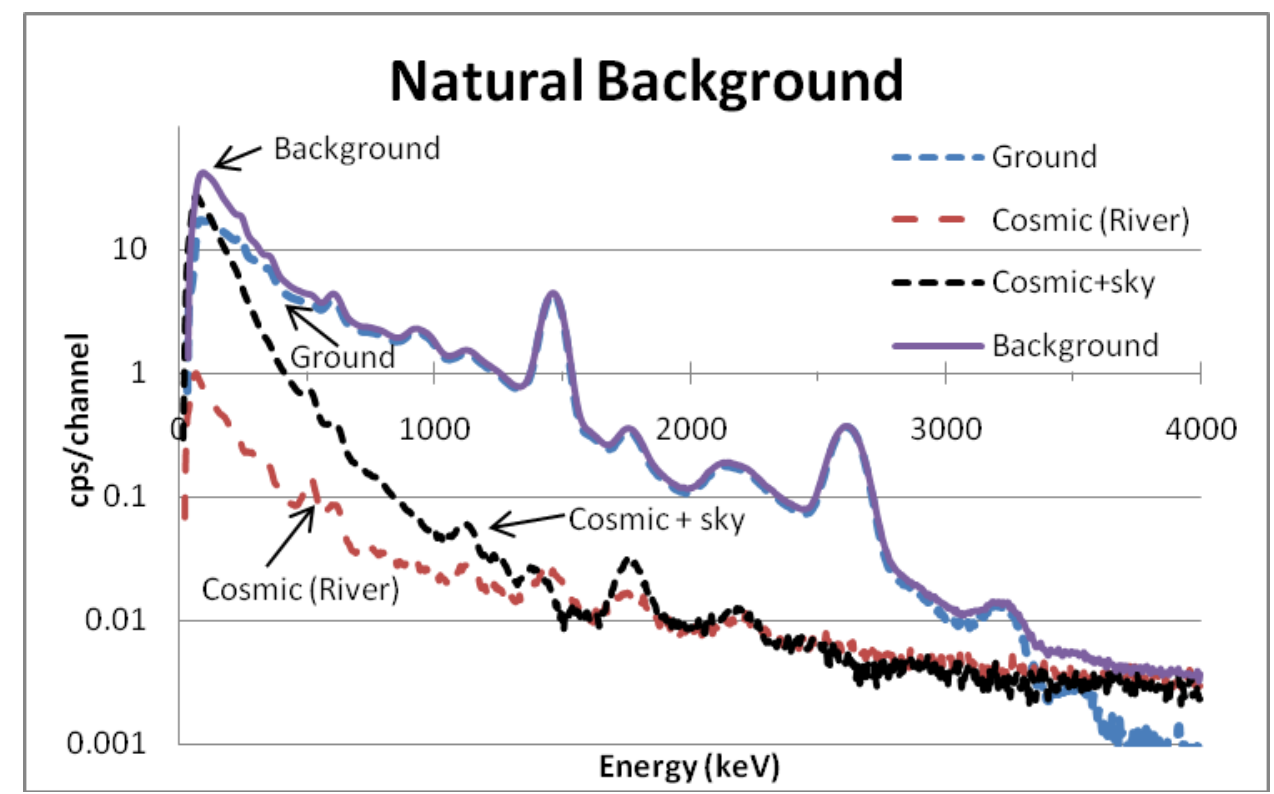

Figure 16. Composite data of natural background

Excluding the terrestrial and cosmic components, skyshine remains. While the skyshine contribution to the total background decreases rapidly above $\sim 50 \mathrm{keV}$, it is important to note that it represents a sizeable, and most decidedly non-negligible, fraction of the composite background $<\sim 500 \mathrm{keV}$. Figure 16 shows that between $\sim 500 \mathrm{keV}$ and $\sim 3300 \mathrm{keV}$, the ground contribution matches the unshielded background well. Above $\sim 3300 \mathrm{keV}$ the cosmic component becomes more dominant.

To better quantify the magnitude of the skyshine contribution, in addition to the geometric corrections to the terrestrial and sky (cosmic plus skyshine) measurements noted earlier, a numerical scaling was applied to the combined cosmic and skyshine data. As suggested by the terrestrial and background plots in figure 16, this correction largely adjusted data in the low energy region. This theoretical fit, summed with the terrestrial contribution, matches the experimentally obtained unshielded background quite well across the entire energy 
range tested (Figure 17). This numerical fit provided an upper bound used to bracket the skyshine contribution to the unshielded background.

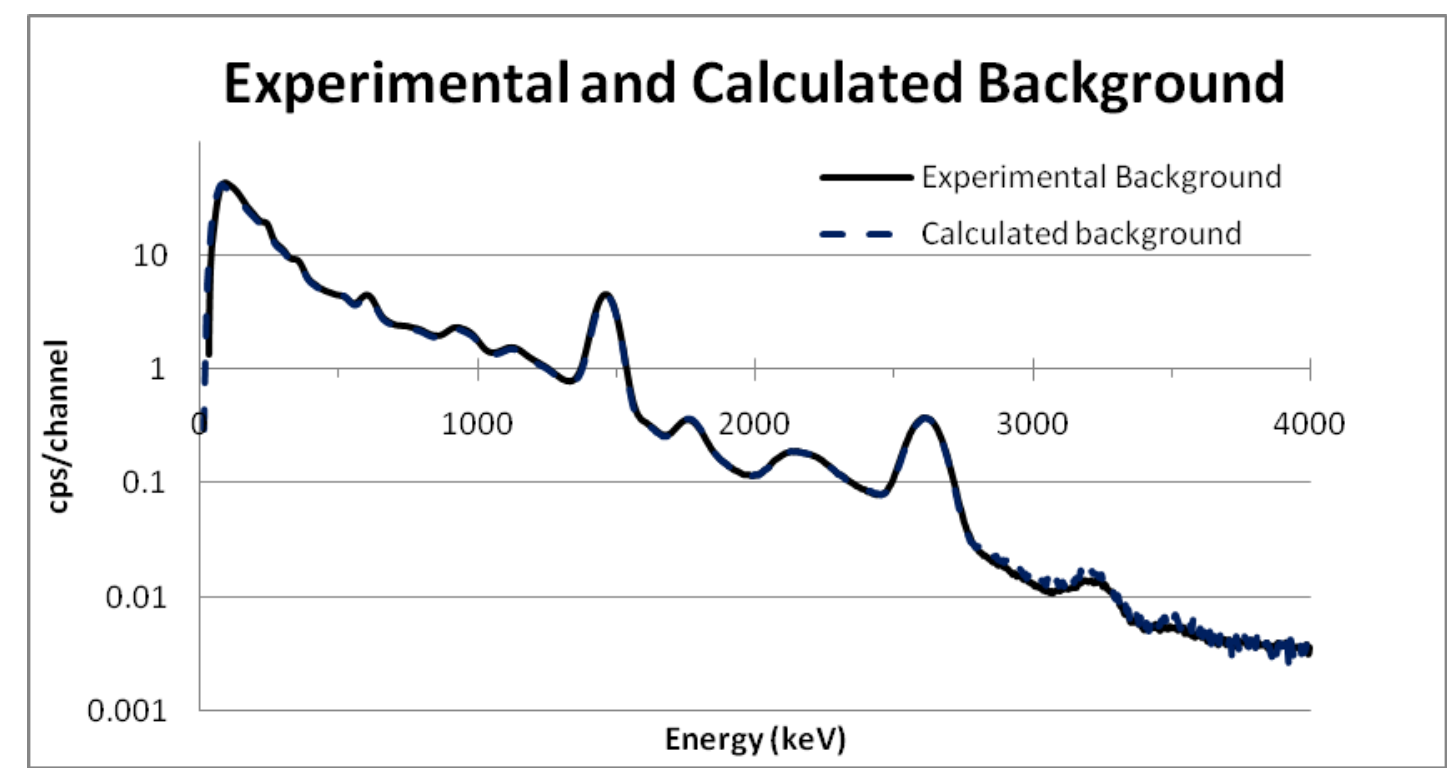

Figure 17. Comparison of Experimental and Calculated Background

Using the experimental data shown in figure 16, and the numerical fit shown in figure 17, limits on the magnitude of the skyshine contribution can be assessed. At $\sim 100 \mathrm{keV}$ skyshine constitutes between $24 \%-49 \%$ of the net unshielded background; at $\sim 200 \mathrm{keV}$ between $18 \%-$ $31 \%$; and at $\sim 300 \mathrm{keV}$ between $6 \%-15 \%$. By $\sim 500 \mathrm{keV}$ skyshine is on the order of the cosmic contribution, and equates to $0 \%-5 \%$ of the background with the terrestrial sources accounting for almost all of the background. These findings are summarized in Table 2 below and reveal the importance of the skyshine contribution to the natural (net unshielded) background over this low energy region. 


\begin{tabular}{|c|c|}
\hline \multicolumn{2}{|c|}{ Table 2. Skyshine contribution to composite background } \\
\hline$\sim 100 \mathrm{keV}$ & $25 \%-50 \%$ \\
\hline$\sim 200 \mathrm{keV}$ & $18 \%-35 \%$ \\
\hline$\sim 300 \mathrm{keV}$ & $5 \%-15 \%$ \\
\hline$\sim 500 \mathrm{keV}$ & $0 \%-5 \%$ \\
\hline
\end{tabular}

Table 2. Skyshine contribution to natural background at various energies $\leq \sim 500 \mathrm{keV}$

\section{Conclusion}

A large $\mathrm{NaI}(\mathrm{Tl})$ detector was used to collect background readings for a number of scenarios and shielding configurations for energies between $0-4 \mathrm{MeV}$. The terrestrial component was, as expected, the dominant factor in the composite background for energies between $\sim 500 \mathrm{keV}$ and $\sim 3000 \mathrm{keV}$. The cosmic (primary and secondary) component was found to be a very small contributor at energies $<\sim 3000 \mathrm{keV}$, but gained relative importance at the terrestrial component diminishes. Above $\sim 3300 \mathrm{keV}$, the cosmic component becomes the main contributor to the natural background in the energy region investigated. The unanticipated result was that skyshine was found to be a significant contributor to the natural background at low energies, potentially contributing up to $50 \%$ of the total background at $\sim 100 \mathrm{keV}$. This suggests that skyshine, which is generally neglected in detection work in the absence of man-made sources, could be a very significant influence affecting radiation detection equipment in the $<\sim 500 \mathrm{keV}$ region. Additional measurements are underway using an HPGe detector, following a methodology similar to that used for the $\mathrm{NaI}(\mathrm{Tl})$ measurements discussed in this paper. 


\section{Acknowledgements}

This work was supported by the Student Undergraduate Laboratory Internship at Pacific Northwest National Lab, U.S. Department of Energy, and by the Juniata College Von Liebig

Foundation. I would like to thank my mentors James Borgardt and Richard Kouzes. I would also like to thank Mitchell Woodring, John Schweppe, and Gerald Sandness for their assistance.

PNNL-18666.

\section{References}

[1] G.A. Bazilevskaya, I.G. Usoskin, E.O. Flückiger, R.G. Harrison, L. Desorgher ·R. Bütikofer, M.B. Krainev, V.S. Makhmutov, Y.I. Stozhkov, A.K. Svirzhevskaya ·N.S. Svirzhevsky,G.A. Kovaltsov, "Cosmic Ray Induced Ion Production in the Atmosphere," Space Sci. Rev., pp. 149$173,2008$.

[2] J.W. Cronin, "Cosmic rays: The most energetic particles in the universe," Reviews of Modern Physics, vol. 71, no. 2, pp. 165-172, 1999.

[3] P.E. Keller, R.T. Kouzes, "Influence of Extraterrestrial Radiation on Radiation Portal Monitors, Nuclear Science, IEEE Transactions on Nuclear Science, vol. 56, pp. 1575-1583, 2008.

[4] G. Knoll, "Background and Detector Shielding," in Radiation Detection and Measurement, $2^{\text {nd }}$ ed. New York: John Wiley \& Sons, 1989, ch. 20, sec. I, pp. 714-719.

[5] R. T. Kouzes, J.H. Ely, E. L. Flumerfelt, W. K. Hensley, K. R. McCormick, E. R. Siciliano, "Skyshine Interference with Radiation Detection," Nuclear Science Symposium Conference Record, 2008. NSS '08. IEEE, pp.1259-1260, 2008.

[6] Livingston \& Blewett, Particle Accelerators, New York: McGraw-Hill, 1962, pp 574-578. 
[7] I.R. Terry, "The Skyshine Benchmark Experiment Revisited," Radiation Protection Dosimetry, vol. 115, pp. 538-541, 2005.

[8] N. Hertel, “A Comparison of Skyshine Computational Methods," Radiation Protection Dosimetry, vol. 116, pp. 525-533, 2005. 



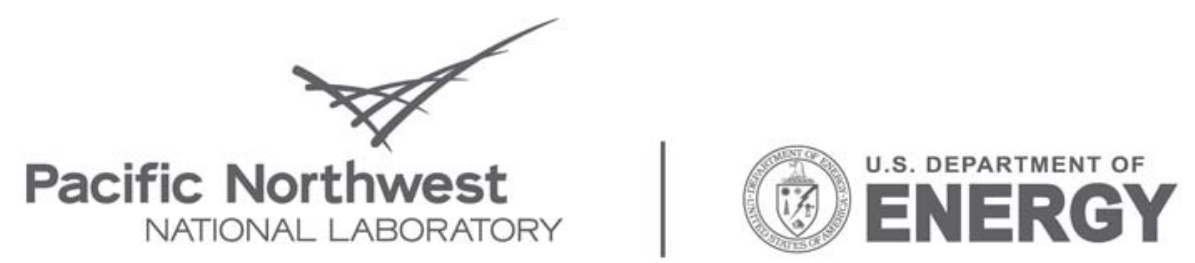

Proudly Operated by Battelle Since 1965

902 Battelle Boulevard

P.O. Box 999

Richland, WA 99352

1-888-375-PNNL (7665)

www.pnl.gov 